\title{
Will Politics be Tweeted? New Media Use by Iranian Youth in 2011
}

\author{
Magdalena Wojcieszak \\ University of Pennsylvania \\ Briar Smith \\ University of Pennsylvania
}

Follow this and additional works at: https://repository.upenn.edu/iranmediaprogram

Part of the Communication Technology and New Media Commons, and the International and Area Studies Commons

\section{Recommended Citation}

Wojcieszak, Magdalena and Smith, Briar. (2013). Will Politics be Tweeted? New Media Use by Iranian Youth in 2011. Iran Media Program.

Retrieved from https://repository.upenn.edu/iranmediaprogram/1

This article was originally published in New Media \& Society. dx.doi.org/10.1177/1461444813479594.

This paper is posted at ScholarlyCommons. https://repository.upenn.edu/iranmediaprogram/1

For more information, please contact repository@pobox.upenn.edu. 


\title{
Will Politics be Tweeted? New Media Use by Iranian Youth in 2011
}

\author{
Abstract \\ A survey of 2,800 Iranian youths regarding their consumption of media and social media indicates that \\ the Internet and state-run television are their primary source for news and information, followed by \\ traditional media and personal connections. Twitter, long thought to be the catalyst of the post-election \\ discontent in 2009, did not show up on the radar of news and information sources. \\ The survey was conducted in 2011 by the Annenberg School for Communication's Center for Global \\ Communication Studies (CGCS) and is reported in the journal New Media \& Society. The article "Will \\ politics be tweeted? New media use by Iranian youth in 2011" by Magdalena Wojcieszak, Ph.D. (Gr '09), IE \\ University in Spain; and Briar Smith, associate director of CGCS, reported on efforts to determine what \\ sources younger Iranians use for information, the extent to which they rely on new media (such as social \\ media) for political exchanges, their experiences with online censorship, and political efficacy as related \\ to new media. The uprisings in Iran following the 2009 contested elections and debate over new media's \\ potential to affect dissent was, in part, a backdrop to the research. The survey was conducted at a time \\ when the "Arab Spring" was taking place, raising the question of whether new media can empower \\ popular protests. \\ Disciplines \\ Communication Technology and New Media | International and Area Studies

\section{Comments} \\ This article was originally published in New Media \& Society. dx.doi.org/10.1177/1461444813479594.
}




\title{
Will politics be tweeted? New media use by Iranian youth in $20 \mathrm{I} I$
}

\author{
Magdalena Wojcieszak \\ IE University, Spain
}

\section{Briar Smith}

University of Pennsylvania, USA

\begin{abstract}
The uprisings after the 2009 elections in Iran generated debate on new media's potential to affect dissent in authoritarian countries. We surveyed 2800 young, educated, metropolitan, and technologically savvy Iranians over a year after the election and during the uprisings in the Middle East and North Africa to examine what sources these youth use for information, the extent to which they rely on new media for political exchanges, their experiences with online censorship, and political efficacy as related to new media. Although the Internet was stated as the most important news outlet, state-controlled television was often used, and Twitter was the least prevalent new media platform. Personal issues and IT/science were more often discussed via new media than politics. Further, it was using new media, not talking politics online, that predicted the frequency with which respondents encountered blocked websites online and also perceptions of their ownpolitical efficacy. Although our findings may support voices that are skeptical about technology's ability to sustain revolution, we also identify what can be described as hubs of politicized Iranian youth.
\end{abstract}

\section{Keywords}

Facebook Revolution, Green Revolution, Internet censorship, Iran, Iranian elections, Iranian public sphere, media consumption, social media use, Twitter Revolution

\footnotetext{
Corresponding author:

Magdalena Wojcieszak, IE School of Communication, IE University, Madrid, Spain.

Email: magdalena.wojcieszak@ie.edu
} 
The popular uprisings that followed the contested 2009 elections in Iran generated substantial discussion on the potential for new information and communication technologies to affect dissent and activist organization in authoritarian countries. The massive upheavals that unfolded and spread through the Middle East and North Africa in 2011 intensified the interest among scholars, the general public, and civil society advocates in how tools such as Facebook, Twitter, and YouTube are used for political strategizing and social mobilization.

Both in Iran and during the collective movements termed the "Arab Spring," some reformist activists deployed new media to encourage compatriots to take to the streets, and there were spikes in online revolutionary conversations before major events on the ground (Howard et al., 2011). These observations contributed to the idea that new media played a central role in these events, a conviction that led to attractive monikers such as "Twitter/Facebook Revolutions."

Other observers, however, were skeptical of claims that the uprisings in Iran and the "Arab Spring" were substantially strengthened by new communication technologies. Some stated that revolutions "will not be tweeted," noting that blogs, Twitter, and Facebook were not used for widespread strategizing and organizing (Gladwell, 2010). These commentators observed that most Twitter feeds after the election originated outside Iran and reminded the public that the states themselves use new media as a means to target their perceived enemies and to advance in the so-called "soft war" (Morozov, 2011).

To some extent, the conclusions drawn depend on where one looks for evidence. An interview with an Iranian political blogger will lead one to conclude that blogs and social media facilitated mobilization. Similarly, analyzing political tweets (see Howard, 2009) will likely lead to overemphasis of the role played by Twitter in Iran and the greater Middle East (Hofheinz, 2011).

In this study, we update and extend this discussion, approaching it from a different angle. We rely on survey data from 2800 young Iranians recruited through an online file-sharing platform in early 2011 in order to shed light on the sources that Iranian youth use for information. We differentiate between traditional media, face-to-face talk, public spaces, and religious leaders, among other potential sources, and also pay particular attention to websites, blogs, Twitter, and text messages. We further examine the topics Iranian youth communicate about via new media to assess the relative prevalence of sociopolitical issues. Moreover, we test the extent of online censorship and of the likely use of circumvention tools, and also analyze whether online activities and experiences of online censorship affect the extent to which new media are linked with individual political efficacy.

This sample, which uses the Internet to a greater extent and at higher speeds than the general population and is technologically savvy, has a collective profile that could well characterize young activists during the uprisings in Iran in 2009, allowing us to examine whether and how Iranian youth employ new media for political purposes in Iran's continually politicized environment. Examining these topics in 2011, over a year after the contested elections and during the uprisings in the greater Middle East, may shed some light on the claims regarding the extent to which people use Twitter or Facebook for political or revolutionary activity. Our study cannot speak to new media use before, 
during, and directly after the contested Iranian election in 2009; nevertheless, one would hope that once engaged with politics on new media platforms, citizens would continue using these media for political exchanges, especially during the wide-scale mobilizing in the region and as sustained economic and political dissatisfaction continued to simmer in Iran (Howard, 2010).

\section{Utopian, dystopian, realistic: new media after the 2009 election in Iran}

After the Iranian presidential elections in June 2009, thousands of people took to the streets in Tehran to protest what they believed was a victory stolen from reformist candidate Mir-Hossein Mousavi by the incumbent, Mahmoud Ahmadinejad. The Iranian government reacted to these uprisings, now known as the Green Movement, by intimidating and arresting journalists and activists and seeking to prevent information reaching the international public. Concurrently, the conservative leadership was spreading propagandistic messages claiming the protests were being encouraged by outside enemies (Fathi, 2010).

In this context, people who had the necessary access and know-how turned to new media to build networks, coordinate protests, spread information, and seek external support. Emphasizing that the protests in Tehran were facilitated by blogs, Twitter, and Facebook, international media quickly rebranded the popular revolt a "Twitter Revolution," with the media asking: "[h] ow did we have revolutions before Twitter?" (Segan, 2009). Some political analysts, following National Journal White House correspondent Marc Ambinder's lead, also cast Twitter as a "protagonal technology that enabled the powerless to survive a brutal crackdown and information blackout by the ruling authorities" (Ambinder, 2009). Former US National Security Adviser Mark Pfeifle stated that Twitter should get the Nobel Peace Prize, because "without Twitter, the people of Iran would not have felt empowered and confident to stand up for freedom and democracy" (in Esfandiari, 2010). The US State Department even reportedly asked Twitter to delay scheduled maintenance to allow Iranians to communicate (Pleming, 2009).

Various factors contributed to making new media an effective tool for activists in Iran, where the median age is 26 and about half of the population is under the age of 35 . Cellphone use is widespread, with nearly $100 \%$ of the population using them (Iran Telecommunications Report, 2012). Moreover, the number of Internet users has been increasing. In 2000, Iran had fewer than one million users; in 2010, over $43 \%$ of Iran's estimated 75 million population used the Internet (Internet World Stats - Usage and Population Statistics, 2011), and between 43\% (BBG/Gallup, 2012) and 47\% (Wojcieszak et al., 2012) reported having Internet access at home in 2012. The Iranian blogosphere is among the fastest growing in the Middle East, and-with more than 700,000 active blogs - Persian is the second most used language in the blogosphere (Baavur-Hendelman, 2007; Bucar and Fazaeli, 2008; Kelly and Etling, 2008; Sreberny and Khiabany, 2007). Furthermore, the government's pervasive censorship of the media has given people additional incentive to turn to the Internet for news and information. 
Were new media protagonists of the post-election uprisings in Iran? Empirical data are limited, yet some evidence suggests that blogs, Twitter, and social networking made a significant difference. Using social network mapping and content analysis, Kelly and Etling (2008) demonstrate that one year before the election, many reformist Iranian bloggers engaged in contentious exchanges with pro-regime bloggers and published oppositional discourse online, despite the repressive environment. Relying on observations or interviews after the election, scholars also show that videos of demonstrations and police brutality that were posted by protesters and later picked up by Western media helped stimulate international support for the Green Movement (Rahimi, 2011), and that social networking sites gave rise to an "exponential expansion of the public domain into cyberspace, to the point that it has had a catalytic, and arguably overwhelming, effect on physical space" (Dabashi, 2010: 135). A correspondent for Al Jazeera English also noted that "[d]espite restrictions on access to Facebook ... around 700,000 users were active from February 2008 to June 2009 ... [and] the BBC says it was receiving around eight videos a minute at the height of the 2009 unrest" (Moshiri, 2011: 30).

Focusing on the 2011 uprisings in Egypt and Tunisia, which share similarities with the events in Iran, Howard et al. (2011) show that social media played a central role in shaping political debates and that increased discussions about democracy and civil rights on Twitter, Facebook, or YouTube often preceded street protests. The authors argue that young, urban, and well-educated citizens employed new media to pressure governments, strategize the best courses of action, and create a "freedom meme" that could "spread ideas about liberty and revolution" to other activists and to international media (Howard et al, 2011: 3). As Howard and Hussain (2011: 36) conclude, "[d]igital media became the tool that allowed social movements to reach once-unachievable goals."

However, many scholars, including those who offer the above evidence, criticize the temptation to attribute instigation of these events to new media as simplistic. Radio Free Europe journalist Golnaz Esfandiari notes, "[s]imply put: There was no Twitter Revolution inside Iran" (2010: 1). Even the manager of Balatarin, a popular Persianlanguage website, was quoted as saying that was "lots of buzz" in the US regarding Twitter's role in Iran, yet "once you look, you see most of it is Americans tweeting among themselves" (in Musgrove, 2009). Also, as protests escalated and the media attributed the coordination of the uprisings to social media, the Iranian government increased filtering of websites, slowed Internet speeds, detained bloggers and reporters, and tapped cellphones (Morozov, 2011). Hence, the election also revealed that using "social media by antigovernment activists, combined with access to highly sophisticated monitoring hardware and software on the part of the Iranian authorities, served to rationalize processes of state surveillance and repression" (Christensen, 2011: 155).

Despite the time that has passed since the Iranian election in June 2009, it is still pertinent to assess media use patterns among Iranian youth. Iran continues to be a volatile country with domestic discontent due to sanctions and dissatisfaction with sociopolitical conditions. Demonstrations break out periodically and are put down by the regime with ruthless efficiency, following the lessons learned in 2009 (Bozorgmehr et al., 2012). The country is currently gearing up for the presidential election in June 2013, which will be a heady period ripe with significance and intense political debate. In this context, the 
Iranian government is on what can be described as permanent high alert against challenges to its authority. Since 2009, the state has further strengthened its control over the media: dozens of newspapers have been shut down and hundreds of journalists, intellectuals, and political dissidents have been exiled or imprisoned. Internet filtering and monitoring of content considered politically or culturally sensitive has become a major government initiative, as has slowing Internet speeds to impede access (Saminejad, 2011). ${ }^{1}$ Reporters without Borders calls Iran the "largest prison for journalists" (2010), and Freedom House (2012) ranks Iran last among the 47 countries assessed in relation to Internet freedom.

In this politically-charged context, little is known about patterns of media use among educated, metropolitan, and technologically savvy Iranian youth, the demographic which has proven to be the most active in the region's political upheaval (see LaGraffe, 2012). What sources and platforms do these youth use for information? Do they rely on new media platforms for political exchanges? Evidence about how youth respond to online censorship is yet more limited due to the sensitive nature of the issue (i.e., circumvention tools are illegal in Iran). It is not known how often young Iranians encounter blocked websites and use tools to circumvent filtering, or whether those who use new media for political purposes encounter filtered content more often (which could indicate their attempts to access sensitive material).

When addressing these issues, it is crucial to locate new media use in the larger context of social capital. While theorizing about these issues in Iran is limited, some observers have noted that analyzing communication flows without attending to the social fabric "is to ignore traditional organizational and group channels which are peculiar to a region's culture" (Mowlana, 1979: 111). In Iran, these channels include mosques and bazaars, where "opinions are formed and from which rumors are spread over wide areas with almost incomprehensible speed" (Mowlana, 1979: 109). Yet, as Howard (2010: 152) notes, "political communication in many Muslim countries is very different from that of even a few years ago," with the Internet strengthening existing groups and allowing people to bridge communities and form new ties. Perhaps, therefore, those Iranian youth who rely on interpersonal networks and public spaces for information are also those who increasingly turn to new media to share it.

In order to address these important and understudied issues and offer a nuanced portrayal of the interactions between new and traditional communication channels in Iran, we surveyed Iranian youth at a point when the political atmosphere was particularly charged: in 2011, with popular uprisings spreading across the Middle East and North Africa and smaller-scale protests and demonstrations still popping up in Iran. We use these data to address four progressively specific research questions, as follows: What information sources are most important for technologically savvy Iranian youth and to what extent do these youth rely on social network sites, blogs, Twitter, and text messages versus friends, family, acquaintances, and mosques, among others $(R Q 1)$ ? What topics do the respondents communicate about via new media $(R Q 2)$ ? How pervasive is the censorship these youth encounter when using the Internet and what factors predict encountering blocked websites $(R Q 3)$ ? Lastly, do young Iranians feel that new media enhance their political self-efficacy, two years after the Green Movement and during the ongoing protests in the region $(R Q 4)$ ? 


\section{Method}

Data for this analysis come from an online survey targeting Iranian youth. The link to the Persian-language survey was included on a file-sharing platform (www.4shared. com) which is the 20th most visited site in Iran (www.alexa.com/topsites/countries/IR). 4shared, which is not filtered in Iran, recognizes its popularity in the country and provides full functionality in Persian. 4shared users can create collections of files which are searchable in Google, effectively making it a huge database of easily searchable content. eBooks in the Persian language, especially those banned inside Iran, are the most popular items.

The link to the survey was promoted via a banner on 4shared, and we offered file storage credit as an incentive to participate. The link was active between March and late April 2011. Overall, 2802 respondents completed the questionnaire. ${ }^{2}$ The sample, by nature of the recruiting platform, is young and technologically savvy. More than $80 \%$ of the respondents are under 30 (14\% 18-20, 39\% 21-25, and 27\% 26-30). A solid majority $(92 \%)$ is male, perhaps reflecting a gender gap in use of the Internet to share content. ${ }^{3}$ Respondents are highly educated, with the majority (78\%) having some type of university degree and almost 20\% having an MA or PhD. They come from Tehran province (37\%), Fars (11\%), and Esfahan (8\%), with other provinces being less represented.

\section{Measures}

Information sources. Respondents were asked where they usually turn for news on politics and current events. The questionnaire provided 12 options (friends and family; neighbors or acquaintances; government officials; taxis; shops and cafes; mosque and religious leaders; print media/newspapers; television; radio; Internet; SMS text messages; and work or school), and respondents could check all options that applied. A follow-up question asked the respondents to select, from the sources indicated, the three most important.

New media use. The survey contained detailed questions about new media. Regarding social networks, respondents were asked whether they have an account on a social networking site, such as Facebook or Cloob (68\% did). Regarding online blogs, respondents reported whether they use the Internet to read web-blogs $(92 \%)$, write comments on blogs written by others (70\%) and write their own blog (54\%). Regarding Twitter, we asked whether, in the past month, respondents had used Twitter to share updates, to see updates about others, or for other activities. Those who had (17\%) were asked how frequently they used it (1="Less than once a month," $2=$ "About once a month," $3=$ "About every two weeks," 4="About once a week," 5="Several times a week but not every day," 6="Every day," 7="Several times a day;" $M=3.22, S D=2.06$ ). We also asked when respondents had started using Twitter (1="less than six months ago," 2="about a year ago," 3="about two years ago," 4="about three years ago," 5="more than three years ago;" $M=2.47, S D=1.40$ ).

Mobile phone use. Respondents were asked whether they have a mobile phone; those who did $(96 \%)$ were asked if they had used it to send or receive text messages in the 
past month. The $99 \%$ who responded in the affirmative were probed about the frequency with which they texted (from 0 "Never" to 7 "Several times a day;" $M=6.01$, $S D=1.32)$.

Communication topics. Those who belonged to a social network, read, commented on or wrote blogs, and/or sent or received tweets and text messages were presented with a list of issues (news and current events; foreign affairs; economy; neighborhood or community; environment; women's rights/gender; lifestyle; personal and everyday life issues; school, work or professional issues; sports; culture; religion; health; social issues; and also science/technology/IT), and asked to check all those they had communicated about over each tested platform during the last month. ${ }^{4}$

Circumvention tools. The survey contained several items about circumvention tools. Respondents were asked how often they came across filtered/blocked websites while using the Internet (0=Never," 1="Rarely," 2="Sometimes," 3="Often," 4="Always;" $M=2.90, S D=1.70)$. The survey probed further, using non-specific language so as not to disincentivize responding: "Some people use various online tools that help circumvent blocked websites. Have you ever heard about such tools?" Those who had (79\%) were asked how easy it would be for them to find and access these circumvention tools (1="Nearly impossible," 2="Very difficult," 3="Difficult," 4="Easy," and 5="Very easy;" $M=3.49, S D=.95$ ) and how secure they would feel using them (1="Very insecure," $2=$ "Insecure," 3="Neither secure nor insecure," 4="Secure," 5="Very secure," $M=2.67$, $S D=1.03$ ). Respondents also rated their ability to use such tools (1="Bad," 2="Poor," 3="Fair," 4="Good," 5="Excellent;" $M=3.66, S D=.97$ ).

Political efficacy. We assessed whether respondents thought that new media make citizens efficacious. The survey stated: "Some people think that new media technologies (e.g., Internet, Twitter, mobile phones) will change the way people influence politics, while others think that this is not the case." Respondents then aligned themselves, from "Disagree Strongly" (1) to "Agree Strongly" (5), with the claim that through new media, "People like me can better understand government and politics" (internal efficacy, $M=3.80$, $S D=1.04)$ and "Public officials will pay more attention to what people like me have to say" (external efficacy, $M=3.13, S D=1.12$ ).

\section{Results}

\section{Information sources}

The survey had four overarching purposes. We assessed where respondents turn for information about politics and current events by providing options ranging from friends and family to shops and cafes and traditional media. Because we sampled Internet users, it is not surprising that we found most of the respondents turn to the Internet for news $(89 \%)$. Television was the second most often selected source $(70 \%)$, followed by friends and family (49\%), print media (42\%), and work or school (33\%). Despite the fact that our sample was young, well educated, and mostly based in metropolitan areas, character- 
istics generally construed by the media as typical of secular Iranians, government officials and religious leaders were also valued sources (18\% and $10 \%$ respectively). ${ }^{5}$

When asked to provide a list of their three most important sources, $56 \%$ of respondents selected the Internet as their first choice, $24 \%$ chose TV, and $7 \%$ chose friends and family. TV was most often selected as the second most important source (31\%), followed by the Internet $(21.5 \%)$ and friends and family (14\%), who were selected as the third most important source by $19 \%$ (followed by the press, $16 \%$, and TV, 14\%). To examine the overall importance of these outlets, we created a variable that assigns value 1 each time a respondent selected a particular source among their three most important. The Internet clearly emerges as the central source for news and information $(85 \%)$, followed by television (67\%) and friends and family (39\%).

We also asked about specific outlets used. Among those for whom the Internet featured in their top three sources, 38\% selected BBC Persian's website, filtered in Iran, as most important, followed by Tabnak (27\%, not filtered) and Balatarin (25\%, filtered). Somewhat surprisingly, among those for whom TV was among the three most important sources, the most popular outlet was the state-run and state-owned IRIB network (selected as most important by $62 \%$ ), followed by BBC Persian (55\%) and Voice of America Persian Network News (30\%).

What about online activities? More respondents reported reading blogs $(92 \%)$ and commenting on blogs $(70 \%)$ than belonging to social networks $(68 \%)$. This might indicate a vibrant online blogosphere, especially considering that more than half of our respondents (54\%) wrote their own blog, even if these blogs were not updated frequently. Among the bloggers, $40.5 \%$ reported updating their blog less than once a month, $17.5 \%$ about once a month, and only $8 \%$ every day or more.

Despite the central role that Twitter was said to play in the uprisings in Iran, it was the least prevalent new media platform used by our sample. Only $17 \%$ reported using Twitter to share or follow tweets. Among the users, most had joined in the past six months (34.5\%), 21\% had started using Twitter about a year previously and only $22 \%$ had started two years previously, coinciding with the contested election. In relation to frequency of use, 33\% shared or followed tweets about once a month, 11\% used Twitter every day, and $7 \%$ used it several times a day.

Cellphones were also credited with fomenting social unrest after the election and correspondents in Tehran reported that the government was preventing access to the cellphone network, attesting to its crucial role (Robinson, 2009). Most respondents (96\%) had cellphones, and nearly all of those (99\%) had used their phone to send messages in the past month (50\% texted several times a day, $21.5 \%$ at least once a day and $20 \%$ several times a week, but not every day).

\section{Discussed topics}

To assess the political potential of new media, it is not sufficient simply to analyze whether people are using various platforms; it is also essential to examine the issues that users communicate about. Political issues did not top the agenda. Respondents did talk about news and current events (44\%), foreign affairs (32\%), community $(25 \%)$, and the economy $(21 \%)$ on social networks; however, these issues were less prevalent than 
personal topics, which were discussed by $54 \%$ of our respondents. Pressing social issues, such as the environment (11\%) or women's rights (10\%), were less often addressed in social networks.

Politics was yet less common in the blogosphere. As Table 1 shows, even though the respondents read blogs about news and current events, foreign affairs or the economy, these topics were far less popular when it came to commenting or posting in the blogosphere. Also, politics was less popular than science/IT, with respondents most often addressing science-oriented issues when commenting on and writing their own blogs. Work-related and social topics were also among the most popular in the blogosphere.

Amongst those who tweeted, news and current events, (selected by $40 \%$ of Twitter users), science/IT issues (38\%) and personal topics (38\%) were equally important. With regard to text messages, unsurprisingly, personal topics emerged as the most prevalent subject (76\%), followed by work (41\%) and social issues $(21 \%)$.

Who was most likely to talk about politics via the platforms analyzed? For each platform (social networks, blogs, Twitter, and text messages), we created a measure indicating communication about strictly political issues (i.e., news/current events and foreign affairs) and predicted it from socio-demographics, being based in Tehran province, having broadband access, dummy variables indicating that a respondent selected a given information source among the three most important, and the two items tapping political efficacy. ${ }^{6}$

As Table 2 shows, older respondents were more likely than their younger counterparts to discuss news and foreign affairs via Twitter. Also, males read and wrote political blogs more often than females. Education was only related to reading political blogs. Having

Table I. Percentage of respondents discussing the various issues through new media.

\begin{tabular}{llllrrr}
\hline & $\begin{array}{l}\text { Social } \\
\text { networks }\end{array}$ & Blogs_read & $\begin{array}{l}\text { Blogs— } \\
\text { comment }\end{array}$ & Blogs—write & Twitter & SMS \\
\hline Community & $25.3 \%$ & $22.2 \%$ & $13.9 \%$ & $9.0 \%$ & $19.3 \%$ & $16.2 \%$ \\
News & $43.8 \%$ & $44.2 \%$ & $30.5 \%$ & $16.6 \%$ & $40.0 \%$ & $15.0 \%$ \\
Foreign Affairs & $31.8 \%$ & $31.3 \%$ & $17.4 \%$ & $9.5 \%$ & $28.4 \%$ & $5.0 \%$ \\
Environment & $10.9 \%$ & $10.5 \%$ & $5.7 \%$ & $4.0 \%$ & $6.1 \%$ & $1.9 \%$ \\
Economy & $19.7 \%$ & $22.8 \%$ & $12.1 \%$ & $7.7 \%$ & $15.7 \%$ & $7.3 \%$ \\
Sport & $27.3 \%$ & $29.2 \%$ & $17.9 \%$ & $9.8 \%$ & $18.6 \%$ & $11.5 \%$ \\
Culture & $30.9 \%$ & $37.0 \%$ & $28.6 \%$ & $27.0 \%$ & $24.6 \%$ & $16.7 \%$ \\
Social & $39.3 \%$ & $40.7 \%$ & $31.9 \%$ & $24.8 \%$ & & $21.1 \%$ \\
Religion & $11.3 \%$ & $20.8 \%$ & $14.4 \%$ & $14.4 \%$ & $8.3 \%$ & $11.9 \%$ \\
Health & $13.2 \%$ & $21.6 \%$ & $8.0 \%$ & $6.5 \%$ & $7.4 \%$ & $4.0 \%$ \\
Personal & $53.8 \%$ & $31.6 \%$ & $29.2 \%$ & $32.7 \%$ & $37.5 \%$ & $75.7 \%$ \\
Work & $31.9 \%$ & $43.5 \%$ & $30.1 \%$ & $27.7 \%$ & $24.2 \%$ & $40.6 \%$ \\
Science & $45.8 \%$ & $61.7 \%$ & $44.4 \%$ & $39.1 \%$ & $37.7 \%$ & $13.1 \%$ \\
Gender & $9.7 \%$ & $10.2 \%$ & $6.4 \%$ & $3.2 \%$ & $9.3 \%$ & $2.1 \%$ \\
\hline
\end{tabular}

Note: Percentages do not add up to $100 \%$ because respondents could select more than one category. 
broadband access was also not a consistent predictor: it was associated with political talk on social networks and-marginally-with blogging about politics. In addition, those respondents who thought that new media make it easier for people to understand politics were more likely than others to discuss politics on social networks, read and comment on political blogs, and share politics via Twitter and text messages. Interestingly, although those who believed that new media can make public officials more attentive could be expected to be more vocal about politics online, political efficacy only predicted political talk via social networks and text messages.

Did the extent to which these youth communicated about politics depend on where they turned for news and current events? In other words, did any particular outlet stimulate political use of new media? Selecting friends and family among the three most important sources was positively related to talking politics on online social networks. In contrast, relying on "weaker ties" such as neighbors, acquaintances and people at work/ school, as well as on taxis, shops, or cafes, was generally unrelated to talking politics via new media.

Did traditional media matter? Not among these respondents. As Table 2 shows, selecting traditional media among the three most important news sources was unrelated to political talk. If anything, the negative coefficients suggest that those who relied on print, $\mathrm{TV}$, and radio talked politics on social networks less than those who ranked these outlets as less important.

Further, although one would expect that using the Internet for news would be related to communicating about politics via new media, it only predicted political exchanges on social networks, and blogs (reading only). ${ }^{7}$ In turn, those who used text messages for information also talked politics on social networks and — naturally—via text.

\section{Circumvention tools}

Our third research question considered circumvention tools - a sensitive topic which we had to address hypothetically. A majority of our respondents $(71 \%)$ reported that they either often (38\%) or always (33\%) found it difficult to access content on the Web and encountered blocked websites. Similarly, a majority (79\%) had heard about tools that help circumvent blocked websites. Among those, 51.5\% said it would be either easy $(37.5 \%)$ or very easy (14\%) to find and access such tools, but many would not feel secure using them (15\% "very insecure" and 26\% "insecure"). When asked to rate their ability to use circumvention tools, most respondents rated it as fair $(34.4 \%)$, good $(34 \%)$, or excellent $(22 \%)$.

Do those who come across blocked websites use new media for different purposes than those who do not? Regression models predicted the frequency of encountering blocked sites from socio-demographics, broadband access, being based in Tehran, and various new media use patterns (social networks, blogs, text messages, and Twitter). Those respondents who used social networks, Twitter, and text messages reported coming across blocked websites more often than those who did not use these platforms. ${ }^{8}$

Who was more likely to express facility with finding and comfort and ability in using circumvention tools? As Table 3 shows, older users reported a lower ability to use such tools, a pattern generally reversed among males, those in the Tehran area, and those with 


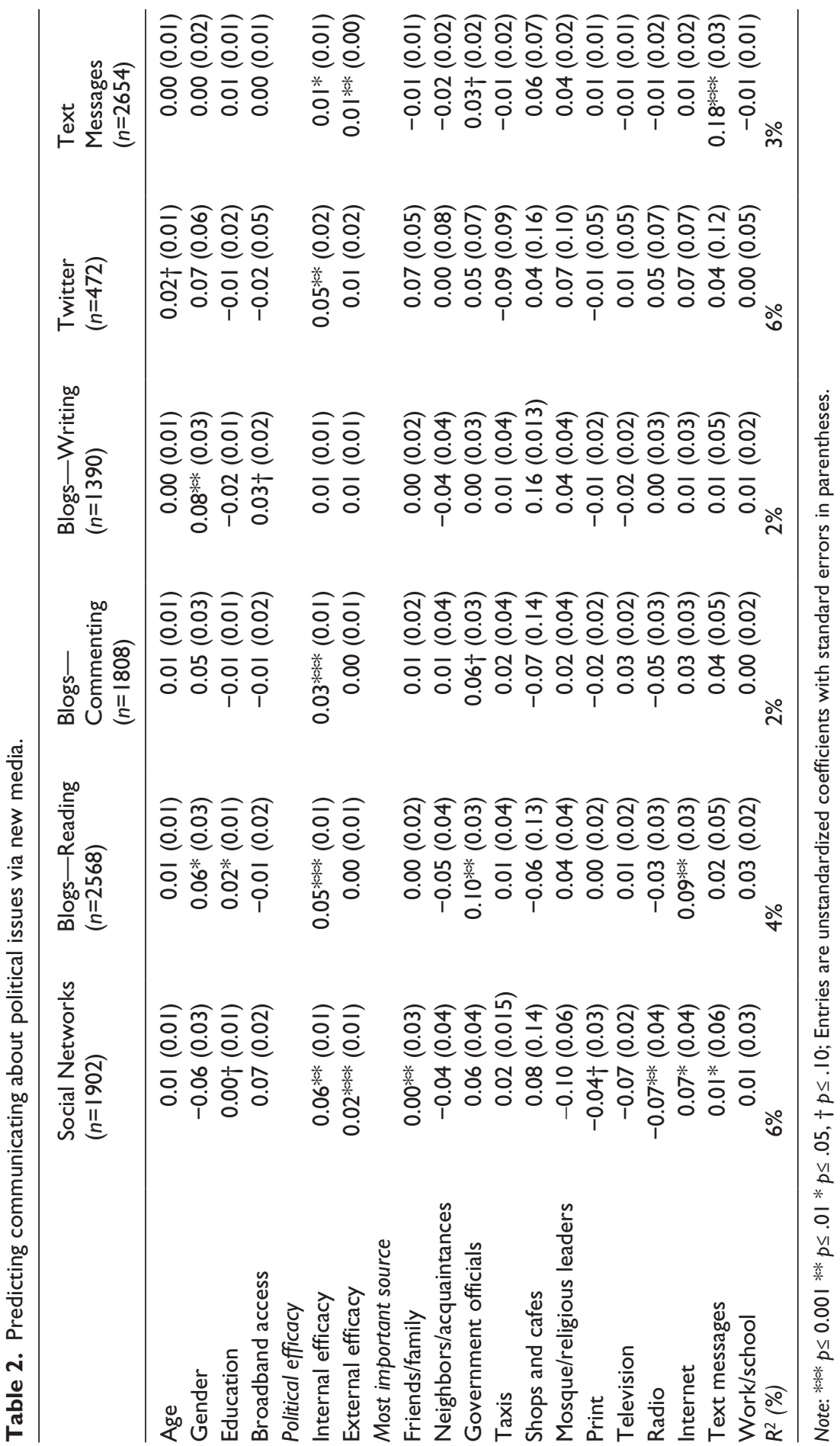


Table 3. Predicting circumvention tools measures.

\begin{tabular}{|c|c|c|c|c|}
\hline & $\begin{array}{l}\text { Encountering } \\
\text { blocked websites } \\
(n=2474)\end{array}$ & $\begin{array}{l}\text { Facility Finding } \\
(n=2052)\end{array}$ & $\begin{array}{l}\text { Security Using } \\
(n=2052)\end{array}$ & $\begin{array}{l}\text { Ability to use } \\
(n=1990)\end{array}$ \\
\hline Age & $0.01(0.02)$ & $-0.03(0.02)$ & $-0.00(0.02)$ & $-0.07 * * *(0.02)$ \\
\hline Gender & $-0.12(0.07)$ & $0.23 * *(0.08)$ & $-0.08(0.09)$ & $0.56 * * *(0.08)$ \\
\hline Education & $-0.01(0.03)$ & $-0.03(0.03)$ & $0.02(0.03)$ & $0.05+(0.03)$ \\
\hline Teheran Province & $0.06(0.04)$ & $0.10 *(0.04)$ & $0.09+(0.05)$ & $0.04(0.04)$ \\
\hline Broadband access & $-0.06(0.05)$ & $0.17 * *(0.05)$ & $0.04(0.06)$ & $0.10+(0.05)$ \\
\hline Social network use & $0.35^{* * *}(0.05)$ & $0.12 *(0.05)$ & $0.07(0.06)$ & $0.35 * * *(0.05)$ \\
\hline Blogs-Reading & $0.09(1.02)$ & $0.57(0.94)$ & $-0.33(1.03)$ & $0.71(0.93)$ \\
\hline $\begin{array}{l}\text { Blogs- } \\
\text { Commenting }\end{array}$ & $0.00(0.05)$ & $0.14 * *(0.05)$ & $0.06(0.06)$ & $0.19 * * *(0.05)$ \\
\hline Blogs-Writing & $-0.06(0.05)$ & $0.01(0.05)$ & $0.04(0.05)$ & $0.11 *(0.05)$ \\
\hline Twitter use & $0.13 *(0.05)$ & $-0.02(0.05)$ & $0.01(0.06)$ & $0.20 * * *(0.05)$ \\
\hline $\begin{array}{l}\text { Text message use } \\
R^{2}(\%)\end{array}$ & $\begin{array}{l}0.03 *(0.02) \\
4 \%\end{array}$ & $\begin{array}{l}0.01(0.02) \\
3 \%\end{array}$ & $\begin{array}{l}-0.01(0.02) \\
1 \%\end{array}$ & $9 \%^{-0.01(0.02)}$ \\
\hline
\end{tabular}

Note: $* * * p \leq 0.001 * * p \leq .01 * p \leq .05, \dagger p \leq .10$; Entries are unstandardized coefficients with standard errors in parentheses.

broadband access. Telling results emerged when it came to new media use. Those who used social networks and commented on blogs felt greater facility accessing circumvention tools than their counterparts who did not use these platforms. Also, those who used social networks, who used Twitter, and who wrote and commented on blogs had a higher ability to use circumvention tools.

Perhaps it was the topics that made some users more likely to encounter blocked content and approach circumvention tools in certain ways? To examine this possibility we retested the above models, entering - in place of the new media platforms - dummy variables representing talking about political issues via the analyzed platforms. With regard to encountering blocked websites, reading political blogs was the only marginal predictor $(b=.08, p<.10)$, and the other political activities in the "new media sphere" were unrelated $\left(R^{2}=5 \%, n=201\right)$. Also, only males $(b=.73, p<.01)$ and those who texted about politics $(b=.42, p<.10)$ said it would be easy to access circumvention tools. In contrast, commenting on political blogs was a negative predictor $(b=-.45, p<.05$, $\left.R^{2}=11 \%, n=193\right)$. The tested items were also unrelated to the security of using circumvention tools $\left(R^{2}=5 \%, n=193\right)$. Lastly, those who commented on political blogs felt less able to use circumvention tools than those who did not engage with such blogs $(b=-.41$, $p<.05)$ and males deemed themselves more proficient at using such tools than females $\left(b=.68, p<.01 ; R^{2}=9 \%, n=190\right){ }^{9}$

\section{Political efficacy}

Lastly, we assessed whether-two years after the election and during the upheavals across the region-Iranian youth thought that new media could change the way people 
influence politics. In general, respondents were more confident that new media could increase people's political understanding (internal efficacy) than that public officials would be more attentive to the citizenry (external efficacy; $M=3.80$ vs. $M=3.13, p<$ $.001)$. To identify those who felt greater efficacy, we predicted the two items from the aforementioned controls, the most important news sources, new media use patterns, and the items related to online censorship and circumvention tools.

As Table 4 shows, in both models, older and better educated respondents and those for whom the Internet was among the three most important news sources expressed greater political efficacy. In contrast, those who relied on neighbors or acquaintances for

Table 4. Predicting political efficacy from new media use patterns.

\begin{tabular}{|c|c|c|}
\hline & Internal efficacy $(n=1982)$ & External efficacy $(n=1982)$ \\
\hline Age & $0.09 * * *(0.02)$ & $0.06 * *(0.02)$ \\
\hline Gender & $0.10(0.08)$ & $0.15(0.10)$ \\
\hline Education & $0.06 *(0.03)$ & $0.06+(0.04)$ \\
\hline Teheran Province & $0.08 \dagger(0.04)$ & $-0.09+(0.05)$ \\
\hline Broadband access & $0.07(0.05)$ & $-0.04(0.06)$ \\
\hline \multicolumn{3}{|l|}{ Most important source } \\
\hline Friends/Family & $0.02(0.06)$ & $-0.01(0.07)$ \\
\hline Neighbors/acquaintances & $-0.20 *(0.10)$ & $-0.19+(0.11)$ \\
\hline Government officials & $-0.14(0.09)$ & $0.13(0.11)$ \\
\hline Taxis & $-0.06(0.11)$ & $-0.08(0.13)$ \\
\hline Shops and cafes & $0.02(0.3 \mathrm{I})$ & $-0.60(0.38)$ \\
\hline Mosque/religious leaders & $-0.27 *(0.12)$ & $0.00(0.15)$ \\
\hline Print & $-0.01(0.06)$ & $0.04(0.07)$ \\
\hline Television & $-0.08(0.05)$ & $0.07(0.06)$ \\
\hline Radio & $-0.09(0.08)$ & $0.20 * *(0.10)$ \\
\hline Internet & $0.37 * * *(0.08)$ & $0.31 * *(0.10)$ \\
\hline Text messages & $-0.07(0.14)$ & $-0.04(0.17)$ \\
\hline Work/school & $-0.05(0.06)$ & $0.10(0.07)$ \\
\hline \multicolumn{3}{|l|}{ New media use } \\
\hline Social network use & $0.13 *(0.05)$ & $-0.01(0.06)$ \\
\hline Blogs_-Reading & $-0.04(0.93)$ & $-0.04(1.12)$ \\
\hline Blogs-Commenting & $0.13^{*}(0.05)$ & $0.02(0.06)$ \\
\hline Blogs-Writing & $-0.08+(0.05)$ & $-0.04(0.06)$ \\
\hline Twitter use & $0.07(0.05)$ & $0.16 *(0.06)$ \\
\hline Text message use & $0.04 *(0.02)$ & $0.02(0.03)$ \\
\hline \multicolumn{3}{|l|}{ Online censorship } \\
\hline Encountering blocked sites & $0.08 * * * *(0.02)$ & $0.01(0.03)$ \\
\hline Circumvention tools-Facility & $-0.03(0.02)$ & $0.00(0.03)$ \\
\hline Circumvention tools-Security & $0.01(0.02)$ & $-0.00(0.03)$ \\
\hline Circumvention tools-Ability & $0.09 * * *(0.02)$ & $-0.00(0.03)$ \\
\hline$R^{2}(\%)$ & $10 \%$ & $3 \%$ \\
\hline
\end{tabular}

Note: $* * * p \leq 0.001 * * p \leq .01 * p \leq .05, \dagger p \leq .10$; Entries are unstandardized coefficients with standard errors in parentheses. 
information were less confident. In addition, the first column shows that social networking, commenting on blogs, and sending texts positively predicted internal efficacy, whereas relying on religious leaders for news was negatively related. With regard to censorship, respondents who often encountered blocked websites and those skilled at using circumvention tools agreed that new media help people to understand politics more than those who rarely came across blocked content and did not report having the skills to circumvent blocked pages. As the second column shows, selecting radio among the most important news sources and using Twitter were positively related to external efficacy, and the other new media variables did not matter.

As above, two final models predicted the two efficacy items from whether respondents discussed politics via new media, socio-demographics and the online censorship items. Those who talked politics on social networks expressed greater confidence that new media increased understanding than those who did not use social networks for politics $(b=.40, p<.05)$, and this was the only significant new media predictor in both models. The censorship-related variables also did not matter (only the ability to use circumvention tools was marginally significant; $b=.13, p<.10)$. Lastly, it was again the educated respondents who felt more efficacious (internal, $b=.41, p<.001$, external $b=.20, p<.10, n=220, R^{2}=16 \%$ and $11 \%$ respectively).

\section{Discussion}

When an election is over, new media habits remain. Elections have become sensitive moments in which student leaders, journalists, and civil society groups experiment with digital technologies. Even if their preferred candidates are not elected, the process of experimentation is important because, by using digital media, citizens construct an information infrastructure that is largely independent of the state. Digital media leave a lasting imprint on civil society, one that continues after elections. The Internet allows youth to learn, for instance, about life in countries where faith and freedom coexist (Howard, 2010).

Following Howard (2010), it might be suggested that new media should continue to be relied upon for political exchanges and social organizing in Iran. This is especially so because the uprisings in the Middle East and North Africa in 2011 also suggested that Twitter and Facebook have the potential to instigate, organize, or at least report on sociopolitical change. Most certainly, this role was occasionally overstated, with some media critics, civil society advocates, and the public talking about alleged "new media revolutions." We contributed to this debate by studying technologically savvy Iranian youth over a year after the election and during the uprisings in the region. We examined their information sources, the topics they discussed via new media, their experiences with online censorship and circumvention tools, and also the beliefs they held about new media's ability to influence the political process.

Our results offer several notable patterns. First, the Internet was the most important news outlet for our sample. Television - especially the state broadcaster-was the second most often used source. This finding is surprising because the surveyed youth map well on to the collective profile of reformist activists who would distrust the government and its sources, suggesting perhaps that this young population is not uniformly 
politicized, mistrustful, or primed for protest, and that despite the fact that the state broadcaster is a mouthpiece for the regime, these young Iranians still watch its content.

Second, despite the claims that Twitter played a central role in the uprisings and the fact that $90 \%$ of Iranian Twitter users live in Tehran, Twitter was the least prevalent new media platform. Our data cannot speak to the extent to which it was employed directly after the contested election. As media use is context-specific, perhaps this very sample would have been tweeting in higher numbers had they been sampled two years prior or during a similar major upheaval. This finding may nevertheless suggest that the central role played by Twitter was overstated. Some analysts allude to this possibility, noting that "if we look at all the [political] movements [...] many of the key players have now left the country" (Valadbaygi, in Esfandiari, 2011: 23) and that "Oxfordgirl [Tweeting in English from outside Iran] was ultimately more successful at gaining publicity for herself than at helping any protesters in Iran" (Esfandiari, 2010). ${ }^{10}$

Our third noteworthy finding is the extent to which these youth use new media technologies for politics. We find that - at least in 2011 - politics was not topping the agenda in the "new media sphere." Again, although new media use habits could have been different during the election, the detected patterns are telling. They suggest that mobilization via new media did not continue and/or was not substantial to begin with, and that our sample was more interested in using blogs, text messages, or Twitter to communicate about personal topics, new technologies and work-related affairs than politics. Reports on mobilization among Iranian youth in 2009, coupled with the popular uprisings in the region at the time the survey was conducted, could lead observers to expect higher politicization on the various new media platforms, but our results indicate that the medium is not always the message.

Speaking to the importance of social capital in twenty-first century Iran, we find that friends and family were not only important information sources, but also that those respondents who talked about politics with their "strong ties" were those who use online social networks for politics. In contrast, acquaintances, coffeehouses, streets, or the marketplace were not used for news, and neither did these weaker ties and the larger public sphere stimulate political exchanges via the new media we analyzed. These telling differences place new media use and the public sphere in context, and substantially extend what is known about information flows in Iran. These findings may suggest that public places are an increasingly uneasy space for information gathering and exchange due to controls on public space and public behavior, related in part to the tense political situation as well as to the culture of guarded behavior in public, which leads the majority of young Iranians to turn to trusted strong ties for political exchanges. These findings also confirm Howard's (2010) observation that the meaning and performance of citizenship has changed with the advent and proliferation of new media.

Two other patterns merit mention. Encountering blocked content online is related more to what new media platforms one uses than to whether one discusses politics online. In line with our other findings, this suggests that talking politics via new media is not necessarily synonymous with accessing and discussing subversive content and that our sample is not uniformly opposed to the regime. Similarly, it is use of some of the tested platforms, and not talking politics, that is related to political efficacy, with the possible 
conclusion that for this sample, using new media per se may be more politically consequential than its actual content.

Taken together, our findings could align with those voices that cast doubts on the extent to which new media swept in the wave of discontent that followed the 2009 presidential election, and the extent to which they have the ability to fuel activist protest and sustain revolution.

However, our results add another layer to our understanding of new media and politics in Iran, underscoring the fact that access to information is inherently political. Our sample often turns to Balatarin and BBC Persian (websites that are filtered and that can only be accessed when one uses illegal circumvention tools) and expresses greater familiarity with and comfort using circumvention tools than does the general Iranian population (Wojcieszak et al., 2012). For these youth, using the Internet is a political act in and of itself, a routine "rebellion" that, while not necessarily overtly challenging the regime, thumbs its nose at attempts to limit information access. As Howard (2010: 164-165) notes, online censorship has essentially politicized various cultural and communicative practices, in that blocking access to Facebook or blogging applications "enrages users, generates some international press coverage, and transforms the online social networking software used by high school students and the most innocuous blogs into resistant political culture."

Also, the people who turn to these filtered websites are the same ones who use social networks, Twitter, blogs, and text messages to discuss politics, and Twitter users, although not numerous, feel that new media may impact government responsiveness to the populace. This finding reveals persisting nodes of plugged-in Iranians. Focusing on such hubs - as many scholars have done - can lead one to overestimate the role played by new media in authoritarian regimes. Our study, broader in scope, may thus more accurately portray the complex interplay between citizens, media, and political powers - an interplay in which not all who are active are uniformly politicized against the regime, where some prefer to be bystanders or passive observers, and where still others foment revolution.

Inasmuch as debates surrounding the role of social media during the Arab Spring "find their genesis in the events that took place in Iran during the summer of 2009" (Christensen, 2011: 155), our study may inform these other cases, showing that in other unstable, wired, and continually politicized contexts and among other educated, metropolitan, and technologically savvy youth, "the heyday of revolutionary activism will pass; everyday life will return, and Internet use will become less "revolutionary", (Hofheinz, 2011: 1427). Our hope is that this study will encourage communication and political science scholars to look broadly for evidence on new media's role in political organizing, and to contextualize this role in the larger fabric of social life. It is studies that attend to the nuanced way in which interpersonal, cultural, and structural factors constitute information flows that can best avoid the tendency to mythologize youth in undemocratic societies and the technologically deterministic narratives where social movements are synonymous with social media.

\section{Acknowledgements}

This study is part of the Iran Media Program at the University of Pennsylvania's Annenberg School for Communication. 


\section{Funding}

This research received no specific grant from any funding agency in the public, commercial, or not-for-profit sectors.

\section{Notes}

1. The Law of Cyber Crimes, approved by Iran's parliament in 2009, is used to prosecute activists and bloggers. The law establishes a range of restrictions on online content, including materials deemed immoral, or anti-Islamic, or that "agitate $[\ldots]$ the opinion of the public, or of the official authorities."

2. The response rate cannot be completed because it is not possible to determine how many people were exposed to the link during the recruitment period.

3. Some studies suggest that there is a gender gap in Internet usage (Bastani and Fazel-Zarandi, 2008). Women also may be more likely to be underrepresented in some online platforms. About $80 \%$ of participants in online networks such as DarsNameh are male and practitioners confirm that there is a gender gap online in Iran, particularly when it comes to more advanced technologies (communication with Small Media Consultancy, a research and advocacy group focusing on Iran).

4. Response options were designed with consultancy from a network of Iranian scholars and activists familiar with the Iranian information ecology. We also incorporated evidence on the topics discussed in the Iranian blogosphere (e.g., Berkman Center Workshop on Iranian Blogosphere, 2007). The translated questionnaire was also pretested and modified as necessary.

5. Submitting all the sources to factor analysis yielded three factors that point to different communication patterns. Interpersonal talk with friends, family, neighbors, and acquaintances, at work or at school; discussions in such public spaces as taxis or in shops and cafes; and SMS use all loaded on one factor (social capital; Eigenvalue 2.61, variance explained 22\%). More traditional or state-related sources such as the press, television, radio, and governmental officials and mosque or religious leaders constituted the second factor (state communication; Eigenvalue 1.42, additional variance $12 \%$ ). Lastly, the Internet loaded on a separate factor (Eigenvalue 1.15, additional variance 10\%). When analyzing these items, the Internet emerged as the most frequently selected source ( $89 \%)$, followed by the state-related channels $(33 \%)$ and "social capital" communication $(20 \%)$; the differences were significant.

6. We also created items indicating broader sociopolitical issues (i.e., news/current events, foreign affairs, the economy, and gender/women's rights). Models predicting such talk yielded parallel results, with some minor differences. Older respondents and females were more likely than their younger and male counterparts to discuss these broader issues on social networks. Also, there were marginally significant associations between turning to shops or cafes for information and talking about these topics on social networks, on blogs, and via text messages.

7. We also re-ran our models, entering a dummy variable representing respondents who selected Balatarin (a blocked website associated with the reformist Green Movement) among the most important websites. Using Balatarin for information was positively related to talking politics via all the tested new media platforms.

8. Because Twitter and Facebook are blocked in Iran, their use necessarily entails using circumvention tools. These associations may thus indicate that these users are accessing other sites that are blocked more frequently or that they encounter more blocked sites because the sites they intend to access are Twitter and Facebook.

9. Additional models that did not include political communication via Twitter (increasing the sample size) found nearly identical coefficients. 
10. It is also possible that, fearing that their online communications were being monitored, some respondents did not answer some questions honestly, underreporting Twitter use. Because respondents freely admitted using Facebook and being familiar with circumvention tools, we have no reason to believe that the low usage of Twitter can be explained by this factor.

\section{References}

Ambinder M (2009) The revolution will be twittered. The Atlantic, 15 June. Available at: http:// www.theatlantic.com/politics/archive/2009/06/the-revolution-will-be-twittered/19376/

Baavur-Hendelman L (2007) Promises and perils of Weblogistan: online personal journals and the Islamic Republic of Iran. The Middle East Review of International Affairs 11(2): 77-93.

Bastani S and Fazel-Zarandi M (2008) The effect of Internet usage on interpersonal relationships: a case study. Observatorio (OBS*) Journal 6: 293-306.

BBG/Gallup (2012) Research series briefing: Iran media use. $B B G / G a l l u p$, June. Available at: http://www.bbg.gov/wp-content/media/2012/06/BBG-Iran-ppt.pdf

Berkman Center Workshop on Iranian Blogosphere (2007) Berkman center workshop on Iranian blogosphere. Harvard University, 6 September. Available at: http://cmes.hmdc.harvard.edu/ node/789

Bozorgmehr S, Lewis J and Sterling J (2012) Riot police swarm anti-Ahmadinejad protesters in fury over currency. CNN News, 2 October. Available at: http://edition.cnn.com/2012/10/03/ world/meast/iran-sanctions-security/index.html

Bucar E and Fazaeli R (2008) Free speech in Weblogistan? The offline consequences of online communication. International Journal of Middle East Studies 40(3): 403-419.

Christensen C (2011) Twitter revolutions? Addressing social media and dissent. The Communication Review 14(3): 155-157.

Dabashi H (2010) Iran, the Green Movement and the USA: The Fox and the Paradox. New York: Zed Books.

Esfandiari G (2010) The Twitter devolution. Foreign Policy, 7 June. Available at: http://www. foreignpolicy.com/articles/2010/06/07/the_twitter_revolution_that_wasnt

Esfandiari N (2011) Censorship. In: Danesh T \& Ansari N (eds.), Iran Human Rights Review: Access To Information. The Foreign Policy Centre. Available at: http://fpc.org.uk/fsblob/1369.pdf

Fathi N (2010) What we got right: against terrible odds, the foreign media did a remarkable job covering the last year's turmoil in Iran. Foreign Policy, 7 June. Available at: http://www. foreignpolicy.com/articles/2010/06/07/what_we_got_right

Freedom House (2012) Freedom on the Net Report. Available at: http://www.freedomhouse.org/ sites/default/files/resources/FOTN\%202012\%20-\%20Full\%20Report.pdf

Gladwell M (2010) Small Change: Why the revolution will not be tweeted. New Yorker, 4 October. Available at: http://www.newyorker.com/reporting/2010/10/04/101004fa_fact_gladwell?current Page $=$ all

Hofheinz A (2011) Nextopia? Beyond revolution 2.0. International Journal of Communication 5: $1417-1434$.

Howard P (2009) Inside the cyberwar for Iran's future. Miller-McCune, 18 December. Available at: http://www.miller-mccune.com/culture/inside-the-cyberwar-for-iran-s-future-6535/

Howard P (2010) The lasting impact of digital media on civil society. U.S. State Department Global E-Journal, 25 January. Available at: http://www.america.gov/st/democracyhr-english/2010/January/20100126140433mlenuhret0.8288081.html

Howard P and Hussain M (2011) The upheavals in Egypt and Tunisia: the role of digital media. Journal of Democracy 22: 35-50.

Howard P, Duffy A, Freelon D, et al. (2011) Opening closed regimes what was the role of social media during the Arab spring? Working paper. Available at: http://pitpi.org/index.php/2011/09/11/ opening-closed-regimes-what-was-the-role-of-social-media-during-the-arab-spring/ 
Internet World Stats - Usage and Population Statistics. (2011) http://www.internetworldstats.com/ stats.htm

Iran Telecommunications Report (2012) Iran telecommunications report. Business Monitor International, 6 March. Available at: http://www.marketresearch.com/Business-MonitorInternational-v304/Iran-Telecommunications-Q2-6844261/

Kelly J and Etling B (2008) Mapping Iran's Online Public: Politics and Culture in the Persian Blogosphere. Internet and Democracy Case Study (Berkman Center Research Publication 200801). Available at: http://cyber.law.harvard.edu/sites/cyber.law.harvard.edu/files/Kelly\&Etling Mapping_Irans_Online_Public_2008.pdf

LaGraffe D (2012) The youth bulge in Egypt: an intersection of demographics, security, and the Arab spring. Journal of Strategic Security 5(2): 65-80.

Morozov E (2011) The Net Delusion: How Not to Liberate the World. New York: Public Affairs.

Moshiri N (2011) New media technology and the uprisings in Iran and Tunisia. In: Danesh T and Ansari N (eds) Iran Human Rights Review: Access to Information. Foreign Policy Centre. Available at: http://fpc.org.uk/fsblob/1369.pdf

Mowlana H (1979) Technology versus tradition: Communication in the Iranian Revolution. Journal of Communication 29(3): 107-112.

Musgrove M (2009) Twitter is a player in Iran's drama. Washington Post, 17 June. Available at: http://www.washingtonpost.com/wp-dyn/content/article/2009/06/16/AR2009061603391.html

Pleming S(2009) U.S. State Department speaks to Twitterover Iran. Reuters U.S.. Available at: http:// www.reuters.com/article/2009/06/16/us-iran-election-twitter-usa-idUSWBT01137420090616

Rahimi B (2011) The agonistic social media: cyberspace in the formation of dissent and consolidation of state power in postelection Iran. The Communication Review 14(3): 158-178.

Reporters without Borders (2010) Imprisonments jump worldwide, and Iran is worst. Available at: http://cpj.org/reports/2011/12/journalist-imprisonments-jump-worldwide-and-iran-i.php\#more

Robinson A (2009) Iran powerless to stop revolution by proxy. $A B C$ News, 9 December. Available at: http://www.abc.net.au/news/2009-12-08/iran-powerless-to-stop-revolution-byproxy/1174832

Saminejad M (2011) Media and Internet under control and censorship. In: Danesh T and Ansari N (eds) Iran Human Rights Review: Access to Information. Foreign Policy Centre. Available at: http://fpc.org.uk/fsblob/1369.pdf

Segan S (2009) Learning from Iran's Twitter Revolution. PC Magazine, 18 June. Available at: http://www.pcmag.com/article2/0, 2817, 2348924,00.asp\#fbid=fqWixGkpyv9

Sreberny A and Khiabany G (2007) Becoming intellectual: the blogestan and public political space in the Islamic Republic. British Journal of Middle Eastern Studies 34: 267-286.

Wojcieszak M, Smith B and Enayat M (2012) Finding a way - how Iranians reach for news and information. Iran Media Program's 2011-2012 report on media consumption in Iran, Center for Global Communication Studies, University of Pennsylvania, PA. Available at: http://www. iranmediaresearch.org/en/research/pdffile/990

\section{Author biographies}

Magdalena Wojcieszak (PhD Communication, Annenberg School for Communication, University of Pennsylvania, MA Sociology, University of Warsaw) is an Assistant Professor at the IE School of Communication, IE University in Spain.

Briar Smith (MA, University of Pennsylvania, BA, Swarthmore College) is Associate Director at the Center for Global Communication Studies at the Annenberg School for Communication at the University of Pennsylvania. 